\title{
1 - Algumas considerações sobre a formação continuada de professores a partir das necessidades formativas em novas tecnologias na educação
}

\author{
Laércia Maria Bertulino de Medeiros \\ Carolina Cavalcanti Bezerra
}

\section{SciELO Books / SciELO Livros / SciELO Libros}

MEDEIROS, LMB., and BEZERRA, CC. Algumas considerações sobre a formação continuada de professores a partir das necessidades formativas em novas tecnologias na educação. In: SOUSA, RP., et al., orgs. Teorias e práticas em tecnologias educacionais [online]. Campina Grande: EDUEPB,

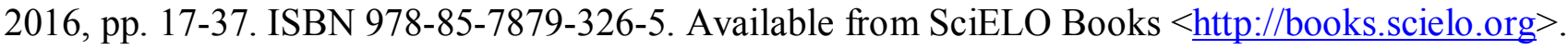

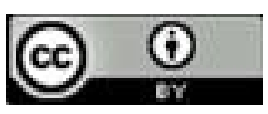

All the contents of this work, except where otherwise noted, is licensed under a Creative Commons Attribution $\underline{4.0 \text { International license. }}$

Todo o conteúdo deste trabalho, exceto quando houver ressalva, é publicado sob a licença Creative Commons Atribição 4.0. 


\section{ALGUMAS CONSIDERAÇÕES SOBRE A}

FORMAÇÃO CONTINUADA DE PROFESSORES A PARTIR DAS NECESSIDADES FORMATIVAS EM NOVAS TECNOLOGIAS NA EDUCAÇÃO

\section{Laércia Maria Bertulino de Medeiros Carolina Cavalcanti Bezerra}

A tentativa de compreender a formação continuada de professores a partir do curso de Novas Tecnologias na Educação, promovido pela Universidade Estadual da Paraíba (UEPB), especificamente vinculado à Pró-Reitoria de Ensino Médio, Técnico e Educação a Distância (PROEA) constitui o objeto deste artigo que possibilita observar, dentre outros, as novas necessidades formativas que hoje, mais que em outras épocas, contribuem para inovações teóricas e uma provável ressignificação da prática pedagógica.

Nesse intento, busca-se articular este objeto com a importância da formação continuada, salientando brevemente as produções acadêmicas dos professores/alunos deste curso, problematizando e configurando o estudo no horizonte de um processo crítico que zela pela relação dialética teoria e prática.

No contexto da aprovação da Lei de Diretrizes e Bases da Educação Nacional (LDB - Lei 9394/96), da qual emergiram novas 
políticas de formação de professores, há tendências para a formação continuada que ao longo de décadas se concretizaram.

Historicamente, as décadas de 1980 e 1990 se configuraram numa época de crítica e superação aos anos anteriores no tratamento das políticas do ensino. A discussão em torno da formação do professor ganhou impulso, resultando em dois grandes movimentos: a revitalização do ensino e o de reformulação dos cursos de Graduação e maior fomento nas pós-graduações no Brasil.

Tendo como referencial a dimensão política da prática docente, a partir dos anos de 1980, emerge outra significação com a aprovação da nova Lei de Diretrizes e Base da Educação, em dezembro de 1996. Aprofundam-se as diferentes propostas para a formação de professores, com o objetivo de elevar os níveis de qualidade da educação. Na reforma do campo da formação, nunca se viu tanto empenho, por parte do governo e de setores das universidades em fazer cumprir o parágrafo $4^{0}$ do artigo 87 das Disposições Transitórias, da Nova LDB que diz: "Até o fim da Década da Educação somente serão admitidos professores habilitados em nível superior ou formados por treinamento em serviço"(BRASIL, 1996).

Nesse sentido, vê-se que paulatinamente se introduziram novos modelos de formação para o ensino superior: cursos sequenciais, educação a distância e outros programas de cunho acadêmico científico.

Em 2000, no X Encontro Nacional da Associação Nacional pela Formação dos Profissionais da Educação (ANFOPE) em Brasília, alertou-se sobre os problemas que as novas políticas governamentais poderiam trazer para a formação do professor:

[...] por entender que as propostas mantêm as fragmentações na formação que enfatiza exclusi- 
vamente o conteúdo específico, as metodologias e o projeto pedagógico da escola, a concepção conteudista, tecnicista do professor, reduzindo-o a um "prático" com pretenso domínio da solução de problemas da prática cotidiana da escola e da sala de aula, alijado da investigação e da pesquisa sobre as condições concretas que geram estes problemas (ANFOPE, 2000, p18).

Assim sendo, a prática do professor debate-se sobre diferentes projetos políticos e perspectivas históricas diferenciadas, o que faz com que a sua formação profissional seja tratada, dentre outras, como elemento impulsionador para a transformação da escola, da educação e da sociedade.

A adequação das Universidades em relação ao novo perfil da educação, apontado nas Diretrizes Curriculares Nacionais, teve no Plano de Desenvolvimento Institucional da UEPB a reforma curricular dos Cursos, além de destacar um novo conceito de gestão (19932000), ao tentar romper com toda a organização tradicional construída a sua volta. Pode-se sinalizar, por exemplo, a preocupação com a sintonia dos objetivos da educação científica com os componentes curriculares apontando para uma visão de educação básica voltada para a formação da cidadania.

Outro intento foi pensar estratégias de ensino que promovessem a interdisciplinaridade, além da proposta de uma multiplicidade de técnicas de ensino e estratégias didáticas com o intuito de possibilitar aos educandos a inserção nas questões sociais e ao interesse científico.

Com base nas discussões nacionais sobre formação docente, outro ponto crucial era pensar o perfil do professor formador voltado, efetivamente para uma nova concepção dos cursos de formação de professores e fomentar a sistematização e operacionalização entre 
ensino, pesquisa e extensão (BRASIL, 1999) como forma de também oferecer aos docentes da UEPB a possibilidade de formações em nível de pós-graduações.

Percebe-se que a formação de professores se confirma como relevante e indica o que Zeichner (2009; apud SLONGO; DELIZOICOV; ROSSET, 2009, p.101) já afirmara ao discorrer sobre essa temática apontando e recomendando a preparação de pesquisadores para estudarem a formação docente, justificando-se que 'Identificar as principais dimensões que precisam ser consideradas para compreender como a formação de professores contribui para determinados resultados educacionais."

Nesse sentido, alguns dos fundamentos teóricos centrais sobre formação de professores em novas tecnologias na educação, apresentados neste artigo, se filiam à perspectiva da teoria crítica e ao princípio freireano da ação-reflexão-ação, tomados como pressupostos que facilitam a efetivação da práxis pedagógica de forma transformadora.

Ao se tomar pressupostos teóricos e metodológicos que influenciam o pensar e o fazer na formação de professores, se reconhece que, como sujeitos do conhecimento, tentam legitimar seu repertório científico na construção e elaboração dessa formação, principalmente na formação continuada. Essa educação, no pensamento de Paulo Freire (1996), representa uma luta por novos significados quanto uma luta em torno de novas competências que assinalem um saber-fazer coerente com as novas demandas sociais.

O saber-fazer releva a importância do professor se assumir como protagonista na construção de alternativas, por ser alguém que processa informações, decide, gera conhecimento prático e possui uma cultura influente na sua atividade profissional. Como García 
(1999, p.47) mesmo confirma em suas palavras que é preciso "considerar o professor como 'um sujeito epistemológico'”. Portanto, há um percurso profissional que não limita o processo de formação docente ao momento de sua formação inicial.

É pertinente considerar o que Nóvoa (1988) discorre ao implicar o professor como adulto que aprende:

O adulto em situação de formação é portador de uma história de vida e de uma experiência profissional [...] Mais importante do que pensar em formar esse adulto é refletir sobre o modo como ele próprio se forma, isto é, o modo como ele se apropria do seu patrimônio vivencial através de uma dinâmica de compreensão retrospectiva (NÓVOA, 1988, p.128).

\section{A FORMAÇÃO CONTINUADA}

Ao se falar sobre formação de professores, percebe-se que historicamente uma concepção que se consolida é a formação continuada. No Brasil, a formação continuada de professores possui uma trajetória histórica e socioepistemológica marcada por diferentes tendências que emergiram de diferentes concepções de educação e sociedade presentes na realidade brasileira. Para Fusari (1998) e Nóvoa (1992), as ideias de formação continuada, vistas como etapa de um único processo:

[...] apontam para a necessidade de se avançar e criar um novo paradigma, no qual a formação do educador se efetive num continuum, processo em que a formação inicial, a formação contínua, a prática profissional, os saberes da profissão e a carreira profissional sejam elementos articulados entre si (FUSARI, 1998, p.538-9; NÓVOA, 1992). 
Na LDB 9394/96, a formação continuada tem por finalidade assegurar aos profissionais da educação o aperfeiçoamento da profissão por meio da intervenção institucional pública (municipal ou estadual), como rezam os artigos:

Artigo 87 (das disposições transitórias) - Cada município e supletivamente, o Estado e a União, deverá:

Parágrafo III- realizar programas de capacitação para todos os professores em exercício, utilizando, também para isso, os recursos da educação a distância.

Artigo 67 (dos profissionais da educação) - Os sistemas de ensino promoverão a valorização dos profissionais da educação, assegurando-lhes, inclusive nos termos dos estatutos e dos planos de carreira do magistério publico (BRASIL, 1996).

Nitidamente nas três últimas décadas, principalmente a partir das políticas para a Educação em todos os níveis, há um incentivo para os profissionais de a educação continuar aprendendo sobre seu campo profissional. A formação continuada passou a "ser considerada como uma das estratégias fundamentais para o processo de construção de um novo perfil profissional de professor"(SILVA; ARAÚJO, 2005; ALTEL, 2001; CANDAU; LELIS, 1999; VEIGA, 1998; ESTRELA; GATTI, 1997; FREIRE, 1996; PIMENTA, 1995; NÓVOA, 1991).

Essa reconfiguração na formação de professores tem repercutido atualmente na construção de identidade do professor, pois revela dentre outras a formalização do saber/dizer científico dos docentes, no seu saber/fazer. Segundo Altet:

A formação não pode mais consistir em uma modelização das tomadas de decisão, mas deve propor dispositivos variados e complementares que desenvolvam o saber-analisar, o saber - refletir, o saberjustificar, através de um trabalho do professor so- 
bre suas próprias práticas e experiências (ALTET, 2001, p.34).

Partindo do pressuposto que a formação do docente deve levá-lo a uma prática social crítica, a formação centralizada numa prática social na ação-reflexão-ação é algo que alimenta a tomada de consciência e de conhecimento por parte do educador.

No entender de Pimenta (1995, p.14), a formação do docente não se esgota nos cursos de formação, pois um curso não é a práxis do futuro professor, ou seja, "um curso não é a prática docente, mas é a teoria sobre a prática docente e será mais formador à medida que as disciplinas todas tiverem como ponto de partida a realidade”.

Em Freire (1996), a formação continuada tem como objetivo incentivar a apropriação dos seus saberes rumo a uma autonomia que o leve de fato a uma prática crítico-reflexiva. Sobre isso afirma que:

Na formação permanente dos professores, o momento fundamental é o da reflexão crítica sobre a prática. É pensando criticamente sobre a prática de hoje ou de ontem que se pode melhorar a próxima prática. O próprio discurso teórico, necessário à reflexão crítica, tem de tal modo concreto que quase se confunde com a prática. O seu "distanciamento" epistemológico da prática, enquanto objeto de sua análise, deve dela "aproximá-lo" ao máximo (FREIRE, 1996, p.39).

No pensamento freireano, a ideia de formação continuada deriva a partir da "condição de inacabamento do ser humano e a consciência desse inacabamento"(FREIRE, 1996, p.40). Diante disso, a formação continuada baseia-se em um processo sucessivo do desenvolvimento profissional do professor formador perante uma interligação entre sua formação inicial, correspondente a sua vivência de aprendi- 
zagem nas instituições formadoras e a continuada, que se configura como processo durante o exercício da profissão.

Segundo Delizoicov (2002 apud RÊGO, 2006, p.80), considerar o professor como sujeito da sua história significa instrumentá -lo para atuar sobre sua prática, envolvendo-o em todos os momentos dessa formação, reconhecendo-o como sujeito de sua prática. Assim, pensar a formação continuada é levar em conta os saberes já constituídos dos professores e as especificidades de suas práticas pedagógicas.

Tardif (2002) afirma que tanto em suas bases teóricas quanto em suas consequências práticas, os conhecimentos profissionais são evolutivos e progressivos e necessitam, por conseguinte, de uma formação contínua e continuada.

\section{UNIDADE ENTRE TEORIA E PRÁTICA}

A concepção e o entendimento da teoria e prática se dão de diferentes formas no que diz respeito aos cursos de formação docente, isto é, circundam pensamentos que veem essa relação ora como opostas, ora como uma relação de justaposição, ora como uma relação de unidade.

Para Freire (1983), a unidade teoria e prática são práxis, isto é, são a ação e a reflexão dos homens sobre o mundo para transformá -lo. E é nesse sentido, que teoria e prática são indissociáveis. Assim, ao se refletir criticamente sobre as novas tecnologias na educação se vislumbra, de fato, como mais um elemento acadêmico científico que na atualidade se faz necessário para o campo da formação do educador.

Pimenta (1995) conceitua práxis inspirada em diversos teóricos, dentre eles Marx que, conceitua práxis como uma atitude teórico-prática do homem de transformação da natureza e da sociedade. 
Não basta conhecer e interpretar o mundo (teórico) é preciso transformá-lo (práxis). Vê-se que práxis se dá num processo dialético que é intencional, consciente e concreto pela ação e reflexão do homem sobre a realidade (CANDAU; LELIS, 1999).

Vasquéz (1977, p.185) ao conceituar práxis diz que: “Toda práxis é atividade, mas nem toda atividade é práxis". Para tanto, a relação entre teoria e prática apresenta-se sob alguns aspectos que são: a prática como fundamento da teoria; a teoria onipotente sobre a prática; a prática como critério de verdade; a prática como atividade subjetiva e objetiva.

Pode-se depreender que, no primeiro aspecto citado, a prática determina a teoria, [....] já que determina o horizonte de desenvolvimento e progresso do conhecimento"(VASQUÉZ, 1977, p.215). É a prática concreta que revela para a teoria seu critério de verdade ou não, pressupondo uma vinculação entre ambas.

Evidencia-se, portanto, que a prática não existe "sem um mínimo de ingredientes teóricos”. De acordo com Vasquéz são:

a) um conhecimento da realidade que é objeto de transformação;

b) um conhecimento dos meios e de sua utilização - da técnica exigida em cada prática -, com que se leva a cabo essa transformação;

c) um conhecimento da prática acumulada, em forma de teoria que sintetiza ou generaliza a atividade prática na esfera em que ela se realize, posto que o homem só pode transformar o mundo a partir de um determinado nível teórico, ou seja, inserindo sua práxis atual na história teórico prática correspondente;

d) uma atividade finalista, ou antecipação dos resultados objetivos que se pretendem atingir sob a forma de finalidades ou resultados prévios, ideais, com a particularidade de que essas finalidades, para que possam cumprir sua função prática, têm 
de corresponder à necessidade e condições reais, têm de tomar conta da consciência dos homens e contar com os meios adequados para sua realização (VASQUÉZ,1977, p.240).

A prática como atividade objetiva e subjetiva vista por Vasquéz (1977, p.242-243) é simultaneamente objetiva e subjetiva, na medida em que "o sujeito não prescinde de sua subjetividade, mas também não se limita a ela; é prático na medida em que se objetiva, e seus produtos são a prova objetiva de sua própria objetivação.”

Nesse sentido, esse movimento não é desprovido de uma intencionalidade consciente, ou seja, a finalidade no processo prático é eminentemente resultado de uma consciência que é dialética:

A prática requer um constante vai-e-vem de um plano a outro, o que só pode ser assegurado se a consciência se mostrar ativa ao longo de todo processo prático. Resulta daí que se é certo que a atividade prática, sobretudo como práxis individual, é inseparável dos fins que a consciência traça, esses fins não se apresentam como produtos acabados, mas sim num processo que só termina quando a finalidade ou resultado ideal, depois de sofrer mudanças impostas pelo processo prático, já é um produto real (VASQUÉZ, 1977, p.243).

A esse respeito, Freire (1983, p.38) acrescenta que: 'Não se pode pensar em objetividade sem subjetividade. Não há uma sem a outra, que não podem ser dicotomizadas”.

A prática como critério de verdade é outro aspecto que é amplamente discutido por Pimenta (1995), ao explicitar o entendimento da unidade teoria e prática sobre a investigação dialética na pesquisa científica que vê o papel da práxis na educação sob quatro aspectos: a intencionalidade da prática; a sua natureza; a necessidade da ação conjunta; e a sua realização efetiva como trabalho humano. 
A intencionalidade da prática refere-se a um fazer consciente, isto é, de acordo com finalidades sobre o mundo concreto num movimento que é dialético.

Outro ponto que se constitui em critério de verdade é a prática social, porque todo o conhecimento e toda ciência só têm fundamento se os fatos que o determinam forem sociais, isto é, sua finalidade, sua construção, seus fins e seus agentes são sociais.

A prática também é uma ação conjunta na medida em que a resolução de problemas científicos complexos pede um envolvimento coletivo dado à profundidade de uma solução individualizada. Vale salientar que o mesmo trabalho pode se dar na ação docente.

Por fim, a prática e a sua realização efetiva como trabalho humano se caracterizam como social, sobretudo, porque é entendida como a ação transformadora da realidade. Assim, a relação de unidade entre teoria e prática é práxis e se dá concretamente na relação intencional, coletiva e social do homem com a realidade que o circunda.

\section{CONTRIBUIÇÕES DA ESPECIALIZAÇÃO EM NOVAS TECNOLOGIAS NA EDUCAÇÃO DA UEPB: AS PRODUÇÕES CIENTÍFICAS}

Ao percorrer teoricamente sobre a formação continuada, faz-se um recorte a respeito da produção científica do curso de Especialização em questão, especificamente no que concerne aos trabalhos de conclusão. Conhecer minimamente o que se produziu ao final de uma jornada revela, dentre outros, o que se configura como temáticas de relevância, como verificar o que ainda é necessário caminhar.

Fez-se um levantamento de dados na biblioteca do polo de Educação a Distância da UEPB em Campina Grande, resultando em 
43 produções de trabalhos de conclusão de curso, no período de 2008 a 2012. Os aspectos balizadores para análise das modalidades de produções foram as temáticas predominantes.

As 43 produções de trabalho de conclusão foram distribuídas em grupos. Criaram-se as seguintes categorias temáticas: Áreas do Conhecimento; Recursos de Multimídia para o Ensino; Jogos Digitais; Formação de Professores; Educação a Distância; Desenvolvimento e Avaliação de Sistema Multimídia; Gestão no Ensino; Sujeitos do Processo de Ensinar e Aprender; Políticas Públicas e Institucionais e os Processos Educativos; Currículo nos Lugares e Espaços Educativos.

CATEGORIA 1: Áreas do conhecimento explicitadas

Foram 17 trabalhos classificados nessa categoria que aqui se definem como "a condição de organização, reorganização, alargamento, aprofundamento e revisão do conhecimento"(BAIBICH-FARIA, 2009, p.735). Essa condição resultou na tabela abaixo:

Quadro 1 - Categoria: áreas do conhecimento explicitadas (continua)

\begin{tabular}{|c|c|c|}
\hline TEMÁTICAS & ANO & TOTAL \\
\hline Geografia & 2008 & 4 \\
\hline Geografia & 2010 & 1 \\
\hline Administração & 2008 & 1 \\
\hline Administração & 2010 & 1 \\
\hline História & 2008 & 1 \\
\hline Matemática & 2008 & 1 \\
\hline Matemática & 2012 & 1 \\
\hline Língua portuguesa & 2008 & 1 \\
\hline Química & 2008 & 1 \\
\hline
\end{tabular}




\begin{tabular}{|c|c|c|}
\hline Microbiologia & 2010 & 1 \\
\hline Ciências Biológicas & 2008 & 1 \\
\hline Comunicação e Educação & 2010 & 1 \\
\hline Geometria & 2010 & 1 \\
\hline Informática & 2011 & 1 \\
\hline
\end{tabular}

FONTE - Arquivo das pesquisadoras

CATEGORIA 2: Uso de recursos e ferramentas didáticas

Define-se essa categoria como a utilização de instrumentos que podem facilitar a construção do conhecimento na prática pedagógica e na pesquisa. Eis a tabela com as referências:

Quadro 2 - Categoria: ferramentas didáticas

\begin{tabular}{|c|c|c|}
\hline TEMÁTICAS & ANO & TOTAL \\
\hline Multimídia para o ensino & $2008 / 2010(2)$ & 4 \\
\hline Ambiente virtual de aprendizagem & 2008 & 2 \\
\hline Jogos digitais & 2008 & 3 \\
\hline Vídeo digital & 2008 & 1 \\
\hline Moodle & 2008 & 1 \\
\hline Tabela periódica eletrônica & 2010 & 1 \\
\hline Infografia & 2010 & 1 \\
\hline Orkut & 2010 & 1 \\
\hline WEBQUEST: & 2010 & 1 \\
\hline Redes Sociais & 2010 & 1 \\
\hline O uso do GVSIG & 2010 & 1 \\
\hline Régua e compasso: software da geometria & 2010 & 1 \\
\hline Webcurrículo & 2012 & 1 \\
\hline
\end{tabular}

FONTE - Arquivo das pesquisadoras 
CATEGORIA 3: Centralidade na educação a distância

Essa categoria é aqui definida como tentativa de compreensão da modalidade de ensino e suas variantes acerca do processo educativo.

Onze (11) trabalhos de conclusão de curso tratam da temática educação a distância sob várias perspectivas. Assim, aqui se optou por listar na íntegra os títulos:

1. A utilização do ambiente virtual de aprendizagem em curso superior a distância;

2. Limites e possibilidades no uso do ambiente de aprendizagem do curso de Geografia a distância;

3. Panorama da educação superior a distância no Brasil: um estudo exploratório.

4. Educação a distância e sua relevância na inclusão social na Universidade Estadual da Paraíba - UEPB;

5. Tutoria: concepções e práticas na educação a distância;

6. O sociointeracionismo no contexto da EAD. A experiência da UFRN;

7. Moodle no curso de ciências biológicas a distância: análise das contribuições no processo de ensino e aprendizagem;

8. Avaliação online na educação a distância: recurso para uma avaliação contínua dos alunos da UEPB do curso de graduação em Administração a distância;

9. Educação a distância. Currículo e interculturalismo: percepção de professores do curso de licenciatura em Geografia;

10. Alunos de EAD: refletindo sobre os ambientes virtuais no curso de Geografia EAD/UEPB; 
11. Gestão em EAD no Ensino Superior: uma avaliação do curso piloto de graduação em administração da SEAD/UEPB.

CATEGORIA 4: Educação, novas tecnologias e outras demandas sociais.

Essa categoria é aqui definida como influência na compreensão das novas tecnologias e seu impacto na educação, na história, na formação pessoal, na formação do professor e do estudante, na inclusão social e gestão.

Catorze (14) trabalhos tratam da temática sob as perspectivas citadas. Aqui também se optou por listar na íntegra os títulos:

1. As concepções de interatividade nos ambientes virtuais de aprendizagem;

2. Ações e estratégias públicas para implementação e o uso de computadores na educação;

3. As novas tecnologias da informação e comunicação no ensino médio profissionalizante: novas perspectivas para a educação e o trabalho;

4. As novas tecnologias da educação frente à inclusão social: um estudo em Campina Grande-PB;

5. Desenvolvimento e avaliação de sistema multimídia para ensino e aprendizado em topografia;

6. A resistência do professor diante das novas tecnologias educacionais;

7. Educação especial em novas tecnologias: caminha para a inclusão?

8. Educação ambiental e tecnologia: aplicação de um SIG na identificação de áreas para aterro sanitário - o uso do GVSIG; 
9. A utilização de recursos multimídias e outras tecnologias para dinamizar o processo de ensino aprendizagem na educação de jovens e adultos;

10. Do volume à tela - O livro, o leitor e a leitura dos primórdios à era digital;

11. Realidade aumentada aplicada à educação: desenvolvimento de um protótipo utilizando rastreamento de mãos;

12. "A fazenda"e a lógica matemática [manuscrito]: a tecnologia no processo de aprendizagem de crianças autistas;

13. Web currículo [manuscrito]: nova cultura de aprender;

14. O uso das novas tecnologias na implementação de projetos inovadores.

Esses trabalhos resultam na síntese consistente do que se considera representativa de uma comunidade epistêmica (ANTONIADES, 2003) e, ao mesmo tempo, a apresentação e as discussões sobre as variantes do conhecimento a partir da especialização em Novas Tecnologias na Educação. 


\section{CONSIDERAÇÕES}

Os trabalhos científicos produzidos pelas comunidades epistêmicas 'têm, potencialmente, a capacidade de influenciar textos políticos e a formação de professores nos contextos de produção de políticas”(LOPES, 2006, p.33-52). Destacou-se, no texto, a importância da formação continuada e os dados disponíveis da produção científica dos trabalhos de conclusão de curso da Especialização em Novas Tecnologias da Educação, da Universidade Estadual da Paraíba.

Ponderou-se sobre a relevância de se considerar as Novas Tecnologias como uma das fontes que podem estar na base do conhecimento da Educação e, assim, sobre a necessidade de pensá-la a partir de sua interseção com outras ciências e com a prática pedagógica.

O diálogo com outras áreas do conhecimento, articuladas com as novas demandas dos cursos de formação, contribui e favorece o trabalho docente dos próprios formadores, a partir do momento em que se mobilizam saberes vindos de fontes heterogêneas.

Em pesquisa realizada por Onofre (2000), ficou demonstrado que o desenvolvimento de programas de formação destinados a professores atuantes pode apresentar um avanço para o campo da formação continuada, uma vez que, privilegiando a troca de experiências e a reflexão sobre a prática tende a tornar a proposta atualizada e pertinente às dificuldades dos docentes.

Assim, sabe-se que qualquer programa de formação continuada se encontra em constante construção, decorrente do próprio princípio articulador entre teoria e prática. Nesse sentido, é que a formação continuada tem se caracterizado como tendência enriquecedora ao desenvolvimento profissional docente. 
Dessa forma, buscou-se resumidamente levantar dados do universo apontado, assim como, algumas reflexões sobre as necessidades formativas dos docentes para atender às novas demandas educacionais.

\section{REFERÊNCIAS}

ALTET, M. et. al. Formando professores profissionais: quais estratégias? Quais competências? 2.ed. Porto Alegre: Artmed Editora, 2001.

ANTONIADES, A. Epistemic comunities, epistemes and the constructions of (world) politics. Global Society, v.17, n.1. Kent: Inglaterra, 2003.

ASSOCIAÇÃO NACIONAL PELA FORMAÇÃO DE PROFESSORES - ANFOPE. Políticas Públicas de formação de profissionais da educação: desafios para a instituição do ensino superior. Documento final do X Encontro Nacional da Associação Nacional pela Formação dos Profissionais da Educação. Brasília, 2000.

BAIBICH-FARIA, T. M. A dimensão teórica da formação dos formadores em didática e práticas de ensino: influências no pensamento contemporâneo e repercussões nas práticas de formação. Avaliação, v.14, n. 3, p.727-753, Campinas: Sorocaba, 2009.

BRASIL. Ministério de Educação e Cultura. Secretaria de Educação Fundamental. Referenciais para formação de professores. Brasília: MEC/SEF, 1999. 
Lei 9394/96, de 23 de dezembro de 1996. Lei de Diretrizes e Bases para a Educação Nacional. Diário Oficial da União. Brasília, DF, 1996.

CANDAU, V. M; LELIS, I. A. A relação teoria-prática na formação do educador. In. CANDAU, V. M. (org). Rumo a uma nova didática. 9.ed. Petrópolis: Vozes, 1999.

ESTRELA, M. T. Viver e construir a profissão docente. Porto: Porto Editora, 1997.

FREIRE. P. Pedagogia da autonomia: saberes necessários à prática educativa. 37.ed. São Paulo: Paz e Terra, 1996.

Pedagogia do oprimido. 13.ed. Rio de Janeiro: Paz e Terra, 1983.

FUSARI, J. C. Formação contínua de professores: o papel do Estado, da universidade e do sindicato. In: ENCONTRO NACIONAL DE DIDÁTICA E PRÁTICA DE ENSINO, 9., 1998, Águas de Lindóia. Conferências, mesas-redondas e simpósios. Petrópolis: Vozes, 1998.

GARCÍA, C. M. Formação de professores: para uma mudança educativa. Porto: Porto Editora, 1999.

GATTI, B. Formação de professores e carreira: problemas e movimentos de renovação. Campinas: Autores Associados, 1997. 
LOPES, A. C. Discursos nas políticas de currículo. Currículo sem fronteiras, v. 6, n. 2, p.33-52, jul./dez.2006. Disponível em: 〈http:// www.curriculosemfronteiras.org/vol6iss2articles/lopes.pdf〉. Acesso em 12 jan. 2013.

NÓVOA, A. Formação de professores e profissão docente. In:

Os professores e a sua formação. Lisboa: Dom Quixote, 1992. p.1333.

Para o estudo sócio-histórico da gênese e desenvolvimento da profissão docente. In. Teoria \& Educação, n.4, p.109 - 133. Campinas, 1991.

NÓVOA, A.; FINGER, M. O método (auto) biográfico e a formação. Lisboa: Ministério da Saúde, 1988.

ONOFRE, M. R. O programa de educação continuada da SEE/SP: 1997-1998 na visão de docentes formadores, professores participantes e especialistas de educação. 2000. 165f. Dissertação (Mestrado) Faculdade de Ciências e Letras, UNESP, Araraquara.

PIMENTA, S. G. O estágio na formação de professores: unidade teoria e prática? 2.ed. São Paulo: Cortez, 1995.

RÊGO, M. C. F. D. A formação docente no fazer e refazer da prática pedagógica. 2006. 71f. Tese (Doutorado) - Centro de Ciências Sociais Aplicadas, Universidade Federal do Rio Grande do Norte, Natal - RN. 
SILVA, E. M. A.; ARAÚJO, C. M. Reflexão em Paulo Freire: uma contribuição para a formação continuada de professores. V Colóquio Internacional Paulo Freire. Recife, 19 a 22 de setembro 2005.

SLONGO, I. I. P.; DELIZOICOV, D.; ROSSET, J. M. A formação de professores nas atas do ENPEC: uma análise preliminar. In: ENCONTRO NACIONAL DE PESQUISA EM EDUCAÇÃO E CIÊNCIAS, VII, 2009, Florianópolis-SC. Anais Eletrônicos. Florianópolis: ABRAPEC, 2009. CD-ROM

TARDIF, M. Saberes docentes e formação profissional. Petrópolis: Vozes, 2002.

VASQUÉZ, A. S. Filosofia da práxis. 2.ed. Rio de Janeiro: Paz e Terra, 1977.

VEIGA, I. P. A. Escola: espaço do projeto político-pedagógico. 4.ed. Campinas: Papirus, 1998.

ZEICHNER, K. M. Uma agenda de pesquisa para a formação docente. Revista Brasileira de Pesquisa sobre Formação Docente, v.1, n.1, p. 1-28, ago/dez. Belo Horizonte, 2009. Disponível em: 〈http://www. formacaodocente.autenticaeditora.com.br $\rangle$. Acesso em 08 set. 2010. 